

Cite this: RSC Adv., 2015, 5, 102981

Received 29th August 2015

Accepted 21st November 2015

DOI: $10.1039 / c 5 r a 17545 c$

www.rsc.org/advances

\section{Polydiacetylene stabilized gold nanoparticles - extraordinary high stability and integration into a nanoelectrode device $\uparrow$}

\author{
R. Liffmann, ${ }^{a}$ M. Homberger, ${ }^{\text {*a }}$ M. Mennicken, ${ }^{b}$ S. Karthäuser ${ }^{b}$ and U. Simon ${ }^{a}$ \\ A new diacetylene containing photopolymerizable ligand molecule was developed, and tailored for \\ applications in nanoelectronic devices based on gold nanoparticles. This ligand molecule consists of \\ a thiol group, a diacetylene unit and a terminal carboxylic group. The thiol group guarantees preferred \\ binding to the gold nanoparticles surface whereas at the same time the carboxylic group enables \\ electrostatic stabilization. Applying this ligand molecule, gold nanoparticles in the size range of 12-13 \\ $\mathrm{nm}$ were prepared. The diacetylene unit was polymerized upon UV irradiation leading to a polymeric \\ ligand shell. Investigations including colloidal stability towards $\mathrm{NaCl}$, DTT displacement reactions, and \\ temperature were performed and indicate an extraordinary high degree of steric and electrostatic \\ stabilization. Individual or at least a few of these particles were immobilized in between nanoelectrodes, \\ thus forming nanoelectronic devices, which were characterized by transport measurements.
}

\section{Introduction}

Ligand stabilized metal nanoparticles are intensively studied objects of the last few decades. ${ }^{1}$ This extraordinary high research interest arises from the unique size dependent properties in combination with the possibility of implementing tailored features, like selective binding ability, aggregation behavior, or bioresponse, by applying appropriate molecules forming the ligand shell. ${ }^{2-6}$

Ligand stabilized gold nanoparticles (AuNP) exhibit high chemical stability and versatile possibilities to implement distinct, additional functionalities into the ligand shell. ${ }^{7}$ As a consequence tailored properties of AuNP with respect to various applications ranging from nanoelectronics, to optical sensors, or biomedical applications, can be realized. ${ }^{8-13}$ The naked gold core itself determines the electrical and optical properties, i.e. Coulomb blockade behavior in the case of AuNP core sizes or plasmon resonance absorption. In this context, we recently studied the $\mathrm{pH}$-dependent reversible aggregation properties as well as the differential adsorption of carboxyl- or amine-terminated AuNP on different metals. ${ }^{14}$ The possibility to control the adsorption characteristics represents a key aspect

\footnotetext{
Institute of Inorganic Chemistry, JARA - Fundamentals of Future Information Technologies, RWTH Aachen University, D-52074 Aachen, Germany. E-mail: melanie.homberger@ac.rwth-aachen.de

${ }^{b}$ Peter Grünberg Institut (PGI-7), JARA - Fundamentals of Future Information Technologies, Forschungszentrum Jülich GmbH, D-52425 Jülich, Germany

$\dagger$ Electronic supplementary information (ESI) available: UV-vis spectra of citrate-AuNP and DA-COOH-AuNP, IRRAS spectra, $\zeta$-potential measurements, Raman spectrum of monomer, UV-vis spectrum of detached particles. See DOI: $10.1039 / \mathrm{c} 5 \mathrm{ra} 17545 \mathrm{c}$
}

for the integration of molecular electronic devices based on functionalized AuNP into traditional CMOS devices. Recently, we succeeded in immobilizing individual ligand stabilized AuNP in between e-beam lithographically fabricated nanoelectrodes by choosing appropriate ligand molecules, ${ }^{15}$ even in a directed manner. ${ }^{16}$ Moreover, the resulting $I / U$-characteristics from these devices directly displayed the molecular transport properties of the ligand molecules. Thus, the electrical properties in such a device depend on the size of the particle, which determines the electrical charging energy, the chemical composition and the length of ligand molecules, as well as the coupling of the molecules to the nanoparticle and the electrodes. So far our results demonstrate that, by choosing tailored ligand molecule-AuNP combinations, the overall transport characteristics in a nanoelectronic device can be adjusted. This fact represents a key step towards the construction of functional nanoelectronic devices like e.g. diodes or switches.

In principle, ligand stabilized AuNP applied in such devices have to fulfill following requirements: (i) the ligand molecules should exhibit not too high electrical resistances in order to allow electrical transport through the device. (ii) Terminal functional groups in the outer sphere of the ligand shell are required that allow proper binding to the electrodes. At the same time, this binding affinity should not exceed the binding affinity of the ligand molecule to the AuNP surface in order to avoid undesired precipitation. ${ }^{17,18}$ (iii) Moreover, regarding the integration and process ability, the applied ligand stabilized AuNP should exhibit a high degree of stabilization towards ligand displacement reactions due to external stimuli, like temperature or solvent treatment, in order to guarantee reliable and reproducible device fabrication. 
Generally, nanoparticle stabilization is achieved either by electrostatic or steric stabilization or combinations of it. Electrostatic stabilization bases on electrostatic repulsion of the diffuse electrical double layer formed around nanoparticles exhibiting surface charges. Steric stabilization bases on geometric constraints around the nanoparticles surface, formed when large and bulky ligand molecules or molecules binding by a polydentate nature to the nanoparticles' surface are applied. According to these concepts highest particle stabilization is achieved when polymeric ligands forming polydentate binding to the AuNP surface and charged groups in the outer ligand sphere, e.g. deprotonated carboxylic groups, are applied.

Up to now several strategies have been developed to enhance the stability of the ligand binding to AuNP and reduce potential ligand desorption or AuNP aggregation. Among these, the predominant strategies are (i) creating crosslinks between terminal functional groups in the outer sphere of the ligand shell, e.g., esterification of terminal carboxylic acid group or (ii) utilizing ligand molecules that form multidentate bonds to the AuNP surface, e.g., molecules bearing multiple thiol groups. ${ }^{19,20}$ However, the first case is accompanied by losing the accessibility of the terminal carboxylic group and the advantage of additional electrostatic stabilization. In the second case a molecular conformation is required where thiol groups with a short spatial distance point into the same direction, otherwise the multidentate nature of the ligand molecule could lead to interparticle cross linking accompanied by undesired particle aggregation.

In this context Kanaras et al. presented an alternative approach leading to extraordinary high stabilized AuNP utilizing diacteylene containing ligand molecules. Diacetylene containing molecules are known to undergo polymerization via 1,4-addition if properly assembled. Thereby in the first step Kanaras et al. prepared AuNP which were stabilized by monomeric diacetylene containing ligand molecules. The formed ligand shell was then internally cross linked upon UV light irradiation, inducing 1,4addition between neighboring diacetylene units. ${ }^{21}$ Thus, a polydentate ligand shell was created. The ligand molecule they used was [46-mercapto-22,43-dioxo-3,6,9,12,15,18-hexaoxa21,44-diazahexatetraconta-31,33-diyn-1-oic acid], a polyethylene glycol derivative. However, though this molecule fulfills the requirement of high stabilization, the molecular length of about $4.7 \mathrm{~nm}$ leads to an expected resistance in the petaohm region. Consequently this ligand molecule is not suitable for applications in nanoelectronic devices.

Another approach published utilized a significantly shorter diacetylene derivative, which seems to be more suitable for nanoelectronic applications, namely 3,5-octadiyne-1-ol-8-thiol. Applying this molecule the authors prepared $5 \mathrm{~nm}$ Janus-type AuNP, whereby the photopolymerizable diacetylene ligand covered one hemisphere of the AuNP surface. ${ }^{22}$ However, according to investigations performed by Evans and coworkers, ${ }^{23}$ the polymerization degree in self-assembled monolayers (SAMs) consisting of diacetylene derivatives immobilized on gold surfaces, decreases significantly with shorter distances between the diacetylene moiety and the anchoring group (spacer length). They observed nearly no polymerization in SAMs consisting of diacetylenes exhibiting spacer lengths of less than four $\mathrm{CH}_{2}$-units.

Based on these findings we developed a new water soluble photopolymerizable diacetylene (DA) containing ligand molecule tailored for implementation in nanoelectronic devices, exhibiting a spacer length of five $\mathrm{CH}_{2}$ units (DA-COOH, Scheme 1a). Thus polymerization is facilitated according to the investigations of Evans and particles are stabilized by a polymeric ligand shell, which ensures steric stabilization due to geometric constraints of the polymer and additional electrostatic stabilization, if the terminal carboxylic group is deprotonated. Furthermore, the thiol anchor group guarantees a preferred binding to the AuNP's surface, due to the well-known significant high binding affinity of thiol to gold surfaces (Au(0)-S: $167 \mathrm{~kJ}$ $\left.\mathrm{mol}^{-1}\right) \cdot{ }^{24}$ The terminal carboxylic acid group ensures the linkage to electrodes in the respective AuNP device. ${ }^{25}$ a)

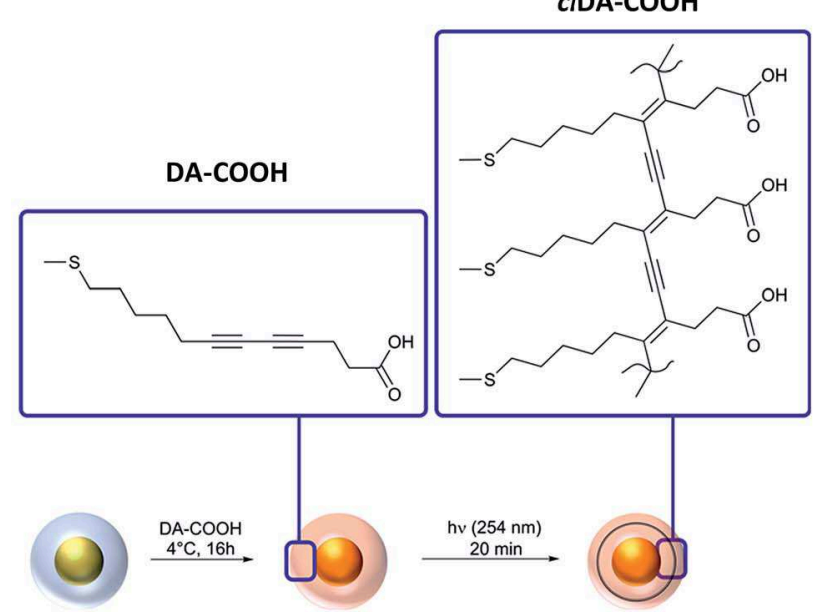

b)

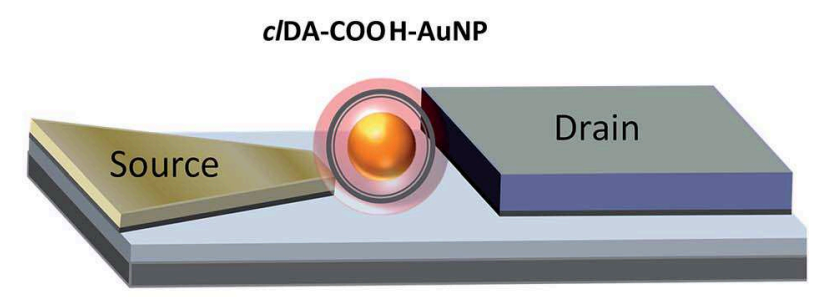

Scheme 1 (a) Preparation of $c / D A-C O O H-A u N P$. (b) Configuration for the electrical characterization of individual $c / D A-C O O H-A u N P$ (not drawn to scale). 
Here, we report on the preparation and characterization of the tailored ligand, DA-COOH and the respective DA-COOHAuNP, before (DA-COOH-AuNP) and after photoinduced polymerization (clDA-COOH-AuNP) (Scheme 1a). We applied AuNP in the size range of $12-13 \mathrm{~nm}$.

The particles were characterized by UV-vis spectroscopy, infrared reflection absorption spectroscopy (IRRAS), surface enhanced Raman scattering, $\zeta$-potential as well as scanning electron microscopy in transmission mode (SEM-T) measurements. Stability investigations were performed including stability towards $\mathrm{NaCl}$, ligand displacement against dithiothreithol (DTT) and heating. As the SPR is sensitive to changes in the ligand shell, particle size and interparticle distance, ${ }^{26}$ these investigations involve mainly UV-vis measurements. Particle aggregation upon decreasing nanoparticle stabilization is reflected by a red-shift and significant broadening, or intensity lost, of the SPR. Transport characteristics of individual clDA-COOH-AuNP were investigated applying the same nanoelectrode setup used in our investigations reported previously (Scheme 1b). ${ }^{15}$

\section{Experimental}

All reagents were purchased either from Acros, Fisher Scientific or Sigma Aldrich and if not mentioned otherwise used without further purification. Ultrapure water with a conductivity $<55 \mathrm{nS}$ $\mathrm{cm}^{-1}$ was used for all procedures.

UV-vis absorption spectra were recorded with a JASCO V-630 spectrophotometer using quartz glass cuvettes.

Dynamic light scattering (DLS) measurements and $\zeta$-potential measurements were performed with a Malvern Zetasizer Nano S, He-Ne laser, $\lambda=633 \mathrm{~nm}, P=4 \mathrm{~mW}, \theta=173^{\circ}$.

IRRAS measurements were performed on a FT-IR spectroscope Vertex 70, Bruker Optics equipped with a MCT detector at a spectral resolution of $4 \mathrm{~cm}^{-1}$.

Scanning electron microscopy (SEM) in transmission mode was conducted with a high-resolution field emission scanning electron microscope (FE-SEM, LEO/ZEISS Supra 35 VP, Oberkochen, Germany). For sample preparation $5 \mu \mathrm{L}$ of the particle solution were dropped on a carbon-coated copper grid and incubated for $30 \mathrm{~min}$. The remaining solution was removed with a tissue.

Raman and SERS spectra were obtained using a HoribaJobin-Yvon Raman spectrometer equipped with Olympus objectives and used at 50 fold magnification and a laser wavelength of $633 \mathrm{~nm}$ at $180^{\circ}$ backscattering arrangement. The spectral resolution was $7 \mathrm{~cm}^{-1}$ and the power on the sample was $12 \mathrm{~mW}$. Particle solution was dropped and dried on a sputtered $\mathrm{Au}$ layer on silicon wafer with a thickness of $100 \mathrm{~nm}$.

TGA measurements were conducted on a Mettler $\operatorname{STAR}^{\mathrm{e}} \mathrm{SW}$ 9.20 instrument. 4-5 mg of dried AuNP and pure DA-COOH ligand were weighed in standard alumina pans, and the measurements were carried out between 25 and $600{ }^{\circ} \mathrm{C}$ at a heating rate of $10^{\circ} \mathrm{C}$ $\min ^{-1}$ under a nitrogen flow of $60 \mathrm{~mL} \mathrm{~min}^{-1}$.

NMR measurements were performed with a Bruker Avance II-400 and Bruker II-HD and referenced to solvent residual signal.

\section{Preparation of diacetylene containing ligand molecules (7)}

Hept-6-yn-1-ol (2). Ethylenediamine (43 mL, distilled) and $\mathrm{NaH}$ (8.565 g $0.2141 \mathrm{~mol}, 60 \%$ on mineral oil) were stirred at 10 ${ }^{\circ} \mathrm{C}$ for $1 \mathrm{~h}$ and Hept-3-yn-1-ol (4.825 g, $0.0430 \mathrm{~mol}$ ) was added dropwise. The resulting slurry was stirred overnight. While the reaction mixture was cooled in an ice bath water $(40 \mathrm{~mL})$ was added and the mixture was extracted three times with ether. The combined organic extracts were washed with $1 \mathrm{~N} \mathrm{HCl}$ solution, sat. sodium bicarbonate and brine, and then dried over $\mathrm{Na}_{2} \mathrm{SO}_{4}$. The product was obtained as a light yellow oil (4.525 g, 0.0403 mol, 93\%). ${ }^{1} \mathrm{H}$ NMR (400 MHz, $\left.\mathrm{CDCl}_{3}\right) \delta(\mathrm{ppm}): 3.66(\mathrm{t}, 2 \mathrm{H}, J=$ $6.5 \mathrm{~Hz}), 2.21(\mathrm{td}, 2 \mathrm{H}, J=6.8 \mathrm{~Hz}, 2.7 \mathrm{~Hz}), 1.95(\mathrm{t}, 1 \mathrm{H}, J=2.7 \mathrm{~Hz})$, 1.75 (s, OH), 1.62-1.43 (m, 7H). ${ }^{13} \mathrm{C}$ NMR (100 MHz, $\mathrm{CDCl}_{3}$ ) $\delta$ (ppm): $84.4(-\mathrm{C} \equiv \mathrm{CH}), 68.3(-\mathrm{C} \equiv \mathrm{CH}), 62.8\left(-\mathrm{CH}_{2}-\mathrm{OH}\right), 32.2$ $\left(-\mathrm{CH}_{2}-\mathrm{CH}_{2}-\mathrm{OH}\right), 28.2\left(-\mathrm{CH}_{2}-\left(\mathrm{CH}_{2}\right)_{3}-\mathrm{OH}\right), 24.9\left(-\mathrm{CH}_{2}-\left(\mathrm{CH}_{2}\right)_{2}-\right.$ $\mathrm{OH}), 18.4\left(-\mathrm{CH}_{2}-\mathrm{C} \equiv \mathrm{CH}\right)$.

7-Iodohept-6-yn-1-ol (3). To a solution of 2 (0.555 g, 4.95 $\mathrm{mmol})$ and potassium iodide $(1.236 \mathrm{~g}, 7.446 \mathrm{mmol})$ in methanol (15 mL), aqueous TBHP (1.28 mL, $9.94 \mathrm{mmol}, 70 \%)$ was added dropwise and stirred at room temperature overnight. The reaction mixture was quenched with sat. aqueous $\mathrm{Na}_{2} \mathrm{~S}_{2} \mathrm{O}_{3}$ and extracted with ethyl acetate. The combined extracts were washed with brine and dried over $\mathrm{Na}_{2} \mathrm{SO}_{4}$. The crude residue was purified by flash chromatography (ethyl acetate/hexane, 1/ $2, \mathrm{v} / \mathrm{v})$ and dried in vacuum which gave 3 as a dark yellow oil (0.725 g, $3.045 \mathrm{mmol}, 62 \%) .{ }^{1} \mathrm{H} \mathrm{NMR}\left(400 \mathrm{MHz}, \mathrm{CDCl}_{3}\right)$ $\delta(\mathrm{ppm}): 3.65(\mathrm{t}, 2 \mathrm{H}, J=6.5 \mathrm{~Hz}), 2.39(\mathrm{t}, 2 \mathrm{H}, J=6.8 \mathrm{~Hz}), 1.63(\mathrm{~s}$, $\mathrm{OH}), 1.62-1.43(\mathrm{~m}, 6 \mathrm{H}) .{ }^{13} \mathrm{C} \mathrm{NMR}\left(100 \mathrm{MHz}, \mathrm{CDCl}_{3}\right) \delta(\mathrm{ppm})$ : 97.45 (I-C $\equiv \underline{\mathrm{C}}-$ ), $62.71\left(\mathrm{HO}-\underline{\mathrm{CH}}_{2}-\right)$, 60.22 (I- $\left.\underline{\mathrm{C}} \equiv \mathrm{C}-\right)$ ), 32.13 (HO$\left.\mathrm{CH}_{2}-\underline{\mathrm{CH}}_{2}\right), 28.22\left(\mathrm{HO}-\left(\mathrm{CH}_{2}\right)_{3}-\underline{\mathrm{CH}}_{2}\right), 24.92\left(\mathrm{HO}-\left(\mathrm{CH}_{2}\right)_{2}-\mathrm{CH}_{2}\right)$, $20.76\left(-\mathrm{CH}_{2}-\mathrm{C} \equiv \mathrm{C}-\right)$.

12-Hydroxydodeca-4,6-diynoic acid (4). Methanol (2 mL) was added to a mixture of pent-4-ynoic acid $(0.138 \mathrm{~g}, 1.41 \mathrm{mmol})$ and $10 \%$ aqueous potassium hydroxide $(1.5 \mathrm{~mL})$. Hydroxylamine hydrochloride $(0.0098 \mathrm{~g}, 0.1410 \mathrm{mmol})$ was added followed by a solution of freshly purified copper(I) chloride (0.035 g, 0.354 $\mathrm{mmol})$ in $70 \%$ aqueous ethylamine $(0.5 \mathrm{~mL})$. The solution was cooled down to $-20{ }^{\circ} \mathrm{C}$ and a solution of $3(0.336 \mathrm{~g}, 1.41 \mathrm{mmol})$ in THF was added dropwise and stirred overnight at room temperature. The reaction mixture was quenched with $10 \%$ sulfuric acid and extracted with ether. The combined extracts were washed with brine and dried over $\mathrm{Na}_{2} \mathrm{SO}_{4}$. The crude residue was purified by flash chromatography (ethyl acetate/ hexane, 2/3, v/v) and dried in vacuum which gave 4 as a light yellow solid (0.158 g, $0.759 \mathrm{mmol}, 54 \%) .{ }^{1} \mathrm{H} \mathrm{NMR}(400 \mathrm{MHz}$, $\left.\mathrm{CDCl}_{3}\right) \delta(\mathrm{ppm}): 5.35(\mathrm{~s}, \mathrm{OH}), 3.67(\mathrm{t}, 2 \mathrm{H}, J=6.5 \mathrm{~Hz}), 2.65-2.55$ $(\mathrm{m}, 4 \mathrm{H}), 2.28(\mathrm{t}, 2 \mathrm{H}, J=6.8 \mathrm{~Hz}), 1.68-1.42(\mathrm{~m}, 6 \mathrm{H}) .{ }^{13} \mathrm{C} \mathrm{NMR}(100$ $\left.\mathrm{MHz}, \mathrm{CDCl}_{3}\right) \delta(\mathrm{ppm}): 176.15(-\underline{\mathrm{COOH}}), 78.05\left(-\mathrm{C} \equiv \underline{\mathrm{C}}-\left(\mathrm{CH}_{2}\right)_{2}-\right.$ $\mathrm{COOH}), \quad 74.79 \quad\left(\mathrm{HO}-\left(\mathrm{CH}_{2}\right)_{5}-\mathrm{C} \equiv \mathrm{C}-\right), \quad 66.13 \quad\left(-\mathrm{C} \equiv \mathrm{C}-\left(\mathrm{CH}_{2}\right)_{2}-\right.$ $\mathrm{COOH}), 65.19\left(\mathrm{HO}-\left(\mathrm{CH}_{2}\right)_{5}-\mathrm{C} \equiv \underline{\mathrm{C}}-\right), 62.73\left(-\underline{\mathrm{CH}}_{2}-\mathrm{OH}\right), 32.73$ (- $\left.\mathrm{CH}_{2}-\mathrm{COOH}\right), 32.01\left(-\mathrm{CH}_{2}-\mathrm{CH}_{2}-\mathrm{OH}\right), 27.97\left(\mathrm{HO}-\left(\mathrm{CH}_{2}\right)_{3}-\underline{C H}_{2}-\right)$, $24.94\left(\mathrm{HO}-\left(\mathrm{CH}_{2}\right)_{2}-\mathrm{CH}_{2}-\right), 19.13\left(\mathrm{HO}-\left(\mathrm{CH}_{2}\right)_{4}-\mathrm{CH}_{2}-\right), 14.91$ $\left(-\mathrm{CH}_{2}-\mathrm{CH}_{2}-\mathrm{COOH}\right)$.

12-(Tosyloxy)dodeca-4,6-diynoic acid (5). Compound 4 (0.503 $\mathrm{mg}, 2.41 \mathrm{mmol})$ was dissolved in chloroform $(10 \mathrm{~mL})$ and cooled to approx. $3{ }^{\circ} \mathrm{C}$. Pyridine $(0.78 \mathrm{~mL}, 9.7 \mathrm{mmol})$ was added 
followed by the addition of $p$-toluenesulphonyl chloride ( 0.689 $\mathrm{g}, 3.61 \mathrm{mmol})$. After complete addition the solution was stirred in an ice bath for additional $2 \mathrm{~h}$ and then stirred at room temperature overnight. The reaction mixture was poured onto a mixture of $\mathrm{HCl}(37 \%)$ and water and was extracted with diethyl ether. The organic extracts were washed with $2 \mathrm{~N} \mathrm{HCl}$, sodium bicarbonate solution (5\%) and dried over $\mathrm{Na}_{2} \mathrm{SO}_{4}$. The product $(0.789 \mathrm{~g}, 2.18 \mathrm{mmol}, 91 \%)$ was used without further purification. ${ }^{1} \mathrm{H}$ NMR $\left(400 \mathrm{MHz}, \mathrm{CDCl}_{3}\right) \delta(\mathrm{ppm}): 7.81(\mathrm{~d}, 2 \mathrm{H}, J=8.2$ $\mathrm{HZ}), 7.37$ (d, 2H, $J=8.0 \mathrm{~Hz}), 4.03(\mathrm{t}, 2 \mathrm{H}, J=6.4 \mathrm{~Hz}), 2.64-2.53$ (m, 4), 2.46 (s, 3H), 2.21 (t, 2H, $J=6.7 \mathrm{~Hz}), 1.69-1.37(\mathrm{~m}, 6 \mathrm{H})$.

12-Iodododeca-4,6-diynoic acid (6). Compound 5 (0.064 g, $0.177 \mathrm{mmol})$ was dissolved in acetone $(0.3 \mathrm{~mL})$. A solution of NaI $(0.053 \mathrm{~g}, 0.354 \mathrm{mmol})$ in acetone $(0.3 \mathrm{~mL})$ was added dropwise at room temperature. The mixture was stirred overnight, quenched with water and extracted with ether. The combined organic extracts were washed with brine and dried over $\mathrm{Na}_{2} \mathrm{SO}_{4}$. Compound 6 was obtained as a yellow solid $(0.050$ $\mathrm{g}, 0.157 \mathrm{mmol}, 89 \%) .{ }^{1} \mathrm{H}$ NMR (400 $\left.\mathrm{MHz}, \mathrm{CDCl}_{3}\right) \delta$ (ppm): 3.19 $(\mathrm{t}, 2 \mathrm{H}, J=7.0 \mathrm{~Hz}), 2.65-2.55(\mathrm{~m}, 4 \mathrm{H}), 2.28(\mathrm{t}, 2 \mathrm{H}, J=6.7 \mathrm{~Hz})$, 1.88-1.81 (m, 4H), 1.60-1.46 (m, 4H). ${ }^{13} \mathrm{C}$ NMR (100 MHz, $\left.\mathrm{CDCl}_{3}\right) \delta(\mathrm{ppm}): 177.11$ (- $\left.\underline{\mathrm{COOH}}\right), 77.79\left(-\mathrm{C} \equiv \underline{\mathrm{C}}-\left(\mathrm{CH}_{2}\right)_{2}-\mathrm{COOH}\right)$, $74.74\left(\mathrm{I}-\left(\mathrm{CH}_{2}\right)_{5}-\mathrm{C} \equiv \mathrm{C}-\right), 66.16\left(-\underline{\mathrm{C}} \equiv \mathrm{C}-\left(\mathrm{CH}_{2}\right)_{2}-\mathrm{COOH}\right), 65.35$ (I$\left.\left(\mathrm{CH}_{2}\right)_{5}-\mathrm{C} \equiv \underline{\mathrm{C}}-\right), 32.97\left(-\underline{\mathrm{CH}}_{2}-\mathrm{COOH}\right), 32.76\left(-\mathrm{CH}_{2}-\mathrm{CH}_{2}-\mathrm{I}\right), 29.68$ $\left(\mathrm{I}-\left(\mathrm{CH}_{2}\right)_{2}-\underline{\mathrm{CH}}_{2}-\right), 27.15\left(\mathrm{I}-\left(\mathrm{CH}_{2}\right)_{3}-\underline{\mathrm{CH}}_{2}-\right), 19.01\left(\mathrm{I}-\left(\mathrm{CH}_{2}\right)_{4}-\mathrm{CH}_{2}-\right)$, $14.86\left(-\mathrm{CH}_{2}-\mathrm{CH}_{2}-\mathrm{COOH}\right), 6.34\left(-\underline{\mathrm{CH}}_{2}-\mathrm{I}\right)$.

12-Mercaptododeca-4,6-diynoic acid (7). Iodide $6(0.054 \mathrm{~g}$, $0.170 \mathrm{mmol}$ ) was dissolved in ethanol $(1 \mathrm{~mL})$ in a round bottom flask under argon. NaSH $(0.066 \mathrm{~g}, 1.18 \mathrm{mmol})$ was added as solid. The suspension was treated with sonication for approx. 10 seconds. The reaction mixture was stirred overnight under argon atmosphere, quenched with acidic water and extracted with ethyl acetate. The combined organic extracts were washed with brine and dried over $\mathrm{Na}_{2} \mathrm{SO}_{4}$. Compound 7 was obtained as a light grey solid (mixture of disulfide and thiol, $0.035 \mathrm{~g}, 0.067$ $\mathrm{mmol}$ (thiol), $0.0470 \mathrm{mmol}$ (disulfide) 39\% with respect to thiol, ratio thiol/disulfide: $1.5 / 1$ by NMR-intensities). ${ }^{1} \mathrm{H}$ NMR (600 $\left.\mathrm{MHz}, \mathrm{CDCl}_{3}\right) \delta(\mathrm{ppm}): 2.68(\mathrm{t}, 2 \mathrm{H}, J=7.4 \mathrm{~Hz}$, disulfide), 2.632.57 (m, 8H, thiol + disulfide), 2.56-2.52 (m, 2H, thiol), 2.29$2.26(\mathrm{~m}, 4 \mathrm{H}$, thiol + disulfide), 1.72-1.67 ( $\mathrm{m}, 2 \mathrm{H}$, disulfide), 1.65-1.60 ( $\mathrm{m}, 2 \mathrm{H}$, thiol), 1.58-1.47 ( $\mathrm{m}, 8 \mathrm{H}$, thiol + disulfide), 1.35 (t, $1 \mathrm{H}, J=7.8 \mathrm{~Hz}$, thiol). ${ }^{13} \mathrm{C}$ NMR (100 MHz, $\mathrm{CDCl}_{3}$ ) $\delta$ (ppm): 177.04 (-ㅡOㄱ), $78.00\left(-\mathrm{C} \equiv \underline{\mathrm{C}}-\left(\mathrm{CH}_{2}\right)_{2}-\mathrm{COOH}\right), 74.67$ $\left(-\left(\mathrm{CH}_{2}\right)_{5}-\underline{\mathrm{C}} \equiv \mathrm{C}-\right), 66.19\left(-\underline{\mathrm{C}} \equiv \mathrm{C}-\left(\mathrm{CH}_{2}\right)_{2}-\mathrm{COOH}\right), 65.23\left(-\left(\mathrm{CH}_{2}\right)_{5}-\right.$ $\mathrm{C} \equiv \underline{\mathrm{C}}-)$, $38.92\left(-\mathrm{S}-\mathrm{S}-\underline{\mathrm{CH}}_{2}-\right), 33.46\left(-\underline{\mathrm{CH}}_{2}-\mathrm{COOH}\right), 32.81\left(-\underline{\mathrm{CH}}_{2}-\right.$ $\mathrm{COOH}), 32.75$ ( $\left.\mathrm{HS}-\mathrm{CH}_{2}-\mathrm{CH}_{2}-\right), 28.80\left(-\mathrm{S}-\mathrm{S}-\mathrm{CH}_{2}-\mathrm{CH}_{2}-\right), 27.80$ $\left(-\mathrm{S}-\mathrm{S}-\left(\mathrm{CH}_{2}\right)_{3}-\mathrm{CH}_{2}-\right), 27.71$ (-S-S- $\left.\left(\mathrm{CH}_{2}\right)_{2}-\mathrm{CH}_{2}-\right), 27.67$ (HS$\left.\left(\mathrm{CH}_{2}\right)_{3}-\mathrm{CH}_{2}-\right), 27.52\left(\mathrm{HS}-\left(\mathrm{CH}_{2}\right)_{2}-\mathrm{CH}_{2}-\right), 24.41\left(\mathrm{HS}-\underline{\mathrm{CH}}_{2}-\right), 19.08$ $\left(-\left(\mathrm{CH}_{2}\right)_{4}-\underline{\mathrm{CH}}_{2}-\equiv \mathrm{C}-\right), 14.86\left(-\mathrm{CH}_{2}-\mathrm{CH}_{2}-\mathrm{COOH}\right)$. Neg.-ESI-MS, $\mathrm{m} / \mathrm{z}$ : calculated: 446.16 (disulfide), 224.1 (thiol), found: 445.2 (disulfide-1), 223.1 (thiol-1).

\section{Preparation of $c l D A-C O O H-A u N P$}

Citrate-stabilized AuNP (citrate-AuNP). Citrate-AuNP were prepared according to the method developed by Turkevich et al. ${ }^{27}$ Tetrachloroauric acid trihydrate $\left(0.050 \mathrm{~g}, 1.3 \times 10^{-4} \mathrm{~mol}\right)$ dissolved in $5 \mathrm{~mL}$ water and sodium citrate dehydrate $(0.125 \mathrm{~g}$, $\left.4.25 \times 10^{-4} \mathrm{~mol}\right)$ dissolved in water $(12.5 \mathrm{~mL})$ were added to boiling water $(250 \mathrm{~mL})$. After $1 \mathrm{~h}$ the resulting deep red solution was allowed to cool down to room temperature and was stored at $4{ }^{\circ} \mathrm{C}$ until use. The SPR absorbance maximum was measured to be $518 \mathrm{~nm}$. The diameter was determined to be $11.3 \mathrm{~nm} \pm 1.1 \mathrm{~nm}$ determined by scanning electron microscopy in transmission mode. The concentration of $\mathrm{Au}$ was measured by atomic absorption spectroscopy to be $87.5 \mathrm{mg} \mathrm{Au}$ per L. The concentration of AuNP was therefore calculated to be $1.8 \times 10^{-8} \mathrm{~mol} \mathrm{~L}^{-1}$.

DA-COOH-AuNP. DA-COOH-AuNP were prepared by a homogeneous ligand exchange reaction under straight light exclusion. Au-citrate $\left(1 \mathrm{~mL}, 1.8 \times 10^{-11} \mathrm{~mol}\right)$ were diluted with water $(1 \mathrm{~mL})$ and DA-COOH ligand $(2 \mu \mathrm{L}, 0.04 \mathrm{mmol})$ in ethanol was added. The particle solution was incubated at $4{ }^{\circ} \mathrm{C}$ overnight. Excess ligand and released citrate were removed by three centrifugation steps (14 $500 \mathrm{rpm}, 15 \mathrm{~min}$ ) and redispersed in $2 \mathrm{~mL}$ of respective buffer which was either phosphate buffer $\left(\mathrm{pH} 8,0.1 \mathrm{~mol} \mathrm{~L}^{-1}\right.$ or $\left.0.01 \mathrm{~mol} \mathrm{~L}^{-1}\right)$ or Hepes/Tris buffer $(\mathrm{pH} 8$, $0.01 \mathrm{~mol} \mathrm{~L}^{-1}$ ).

clDA-COOH-AuNP. Photochemical polymerization was initiated by exposing a solution of DA-COOH-AuNP in a $1 \mathrm{~cm}$ quartz glass cuvette to a UV lamp $(254 \mathrm{~nm}, 6 \mathrm{~W})$ at a distance of $10 \mathrm{~cm}$ from lamp for $15 \mathrm{~min}$.

pH dependent $\zeta$-potential measurements. Freshly prepared irradiated DA-COOH-AuNP were redispersed in phosphate buffer (0.01 mol L $\left.\mathrm{mH}^{-1}, \mathrm{pH}, 7,9\right)$.

Reversible pH dependent aggregation. $1 \mathrm{~mL}$ freshly prepared irradiated DA-COOH-AuNP were redispersed in water and adjusted to a $\mathrm{pH}$ of 9 with $10 \mu \mathrm{L}$ sodium hydroxide solution $\left(0.1 \mathrm{~mol} \mathrm{~L}^{-1}\right)$. A spectrum was taken and the sample was acidified with $10 \mu \mathrm{L}$ hydrogen chloride solution $\left(0.1 \mathrm{~mol} \mathrm{~L}^{-1}\right)$ resulting in a $\mathrm{pH}$ of 3 . A spectrum was taken and the procedure was repeated so that the $\mathrm{pH}$ was alkaline for three times.

Quantification of thiols on nanoparticles' surface. $80 \mathrm{~mL}$ of clDA-COOH-AuNP were synthesized and redispersed in ultrapure water ( $\mathrm{pH}$ set to 8 with sodium hydroxide solution). Particles were concentrated, filled in a standard alumina pan and dried in a desiccator.

\section{Stability investigations}

Stability towards NaCl. Freshly prepared irradiated and nonirradiated DA-COOH-AuNP in phosphate buffer solution $(0.1 \mathrm{M}$, pH 8) were mixed with sodium chloride solution, so that the final concentration were $0.15 \mathrm{~mol} \mathrm{~L}^{-1}$, and $0.3 \mathrm{~mol} \mathrm{~L}^{-1} \mathrm{NaCl}$ and mixed thoroughly. The first measurement was taken after 5 minutes of mixing and incubation. Spectra were recorded every 5 minutes for $1 \mathrm{~h}$. Zero minute spectra were recorded by adding the same volume of water instead of sodium chloride solution. Non-irradiated AuNP were kept under strict light exclusion prior to measurement.

DTT competition. Freshly prepared irradiated and nonirradiated DA-COOH-AuNP in phosphate buffer solution (0.1 M, pH 8) were mixed with DTT solution so that the final concentration of DTT was $2 \mathrm{mmol} \mathrm{L}^{-1}$. Assuming a density of 2800 ligand molecules/NP the ratio of ligand/DTT was $1 / 50$. 
Reference samples were prepared by adding the same amount of water instead of DTT solution. Particle and reference samples were incubated at $60{ }^{\circ} \mathrm{C}$ for $12 \mathrm{~h}$ and then measured. Nonirradiated samples were kept under strict light exclusion prior to measurement.

Thermal stability. For continuous heating 5 samples of freshly prepared irradiated DA-COOH-AuNP in Hepes/Tris buffer $\left(0.01 \mathrm{~mol} \mathrm{~L}^{-1}, \mathrm{pH} 8\right)$ were sealed in a plastic vial and incubated in a vial heating device equipped with a thermometer preheated to $50{ }^{\circ} \mathrm{C}$ and $80{ }^{\circ} \mathrm{C}$. Every hour one sample was removed, directly cooled with ice/water and measured.

For heating cycles freshly prepared irradiated DA-COOHAuNP were sealed in a plastic cuvette and placed in the DLS device. The heating range was $20-70{ }^{\circ} \mathrm{C}$. The heating rate was set to $5{ }^{\circ} \mathrm{C} / 10 \mathrm{~min}$ and the final temperature $\left(20^{\circ} \mathrm{C}, 70{ }^{\circ} \mathrm{C}\right)$ was maintained for $1 \mathrm{~h}$. Three heating/cooling cycles were performed.

\section{Electrical characterization of individual polydiacetylene stabilized AuNP in a heterometallic nanogap}

In order to electrically characterize the prepared $c l \mathrm{DA}-\mathrm{COOH}-$ AuNP, individual or at least a few AuNP were immobilized in between heterometallic nanoelectrodes. Nanoelectrode pairs were processed by a multiple step E-beam-lithography process combined with a self-alignment procedure on $\mathrm{a} \mathrm{SiO}_{2}$ surface as described previously. ${ }^{15,28}$ The received heterometallic nanoelectrode pairs consist of one Pt- and one AuPd-electrode and exhibit gap sizes in the range of 10 to $14 \mathrm{~nm}$. In order to deposit AuNPs in between the nanoelectrodes a $15 \mu \mathrm{L}$ droplet of $c l \mathrm{DA}$ $\mathrm{COOH}$-AuNP dissolved in phosphate buffer solution at $\mathrm{pH} 8$ was dropped on a $6 \times 6 \mathrm{~mm}^{2}$ sample surface with 48 nanogaps. Individual or at least a few $c l \mathrm{DA}-\mathrm{COOH}-\mathrm{AuNP}$ were immobilized using capillary forces during the drying process of the AuNP solution. ${ }^{29}$ Subsequently, the sample was washed with DI-water to remove residual buffer solution and blown dry with nitrogen. Electrical characterization was performed with a Keithley 6430 sub-femtoampere remote source meter at room temperature under ambient conditions. Cyclic current/voltage $(I / U)$ measurements were recorded with the Pt-electrode connected to ground and a cyclic voltage applied to the AuPd-electrode.

\section{Results and discussion}

\section{Preparation of DA-COOH}

The diacetylene derivative DA-COOH (Scheme 1a) was synthesized involving six reaction steps, as depicted in Scheme 2. In the first step hept-3-yn-1-ol (1) was converted into the respective $\omega$-alkyne-ol (2) adopting the so-called "Alkyne-Zipper"30 reaction. After substituting the acidic alkyne proton of 2 by iodine, we applied the "Cadiot-Chodkiewicz" ${ }^{31}$ coupling of compound 3 with pent-4-ynoic acid resulting in the diacetylene precursor 4 (DA-OH). This reaction step as well as the following steps was performed under light exclusion in order to avoid uncontrolled photoinduced polymerization. In the following the alcohol functionality was converted into the corresponding thiol involving tosylation, nucleophilic substitution with iodine (NaI) and finally, the reaction with sodium hydrogen sulfide. DA$\mathrm{COOH}$ was obtained as a pale yellow solid. The last step, the conversion into the thiol, was performed in Ar atmosphere applying dry ethanol, due to the well-known tendency of thiols to form disulfides upon oxidation under ambient atmosphere. ${ }^{32}$ Especially primary alkanethiols are known to be more sensitive towards oxidation than tertiary alkanethiols. However, although we performed the reaction extremely carefully in Ar atmosphere under light exclusion, ${ }^{1} \mathrm{H}$-NMR measurements of the obtained product always revealed a significant amount of the respective disulfide (about 40\%, see Experimental section). Several attempts to get rid of the disulfide or at least to lower the content were not successful. However, since it is well-known that disulfides adsorb on gold surfaces ${ }^{33}$ in the same way as thiols, the obtained thiol/disulfide mixture was used in the following reactions.

\section{Preparation of $c l \mathrm{DA}-\mathrm{COOH}-\mathrm{AuNP}$}

In the first step of the preparation of $c l \mathrm{DA}-\mathrm{COOH}$-AuNP, citrateAuNP (11.3 nm $\pm 1.1 \mathrm{~nm}$ ) were subjected to a homogeneous ligand exchange reaction. The ligand exchange reaction was performed overnight at $4{ }^{\circ} \mathrm{C}$ applying an excess of DA-COOH, thereby carefully excluding light in order to avoid uncontrolled photoinduced polymerization at this point.

Ligand excess as well as released citrate was removed by repeatedly centrifugation and redispersion in phosphate buffer solution (0.1 M, pH 8) at ambient temperature under light exclusion. The alkaline medium was chosen in order to avoid agglomeration due to poor electrostatic stabilization of the carboxylic acid terminated AuNP at lower $\mathrm{pH}$ values. The obtained DA-COOH-AuNP were characterized by UV-vis spectroscopy and infrared reflection absorption spectroscopy (IRRAS). UV-vis spectra (see ESI $\dagger$ ) revealed a red-shift of the surface plasmon resonance absorption (SPR) maximum of $4 \mathrm{~nm}$ with respect to the starting material, reflecting the modified ligand binding situation (carboxyl towards thiol). For IRRAS measurements the aqueous dispersion was incubated for $2 \mathrm{~h}$ on a solid support. In the IRRAS spectrum the characteristic absorption bands for the DA-COOH were detected at $2929 \mathrm{~cm}^{-1}$, $2857 \mathrm{~cm}^{-1}, 1783 \mathrm{~cm}^{-1}$ and $1573 \mathrm{~cm}^{-1}$, whereby the absorptions at $1783 \mathrm{~cm}^{-1}$ and $1573 \mathrm{~cm}^{-1}$ can be assigned to $\mathrm{COOH}$ stretching vibrations $(\nu(\mathrm{CO})$ and $\nu(\mathrm{CO}-\mathrm{H}))$. The absorption at $2929 \mathrm{~cm}^{-1}$ and $2857 \mathrm{~cm}^{-1}$ arise from $\mathrm{CH}_{2}$ stretching vibrations $\left(\nu_{\text {as }}\left(\mathrm{CH}_{2}\right)\right)$ and $\left(\nu_{\mathrm{s}}\left(\mathrm{CH}_{2}\right)\right) \cdot{ }^{34}$ Additionally, the characteristic vibration for the citrate-AuNP at $1394 \mathrm{~cm}^{-1}$ cannot be observed which indicates complete ligand exchange (see ESI $\dagger$ ).

In order to induce cross-linking within the DA-COOH ligand shell, the DA-COOH-AuNP were exposed to UV light (254 nm, 6 W) for $15 \mathrm{~min}$. No change of the initially red coloured particle dispersion was observed during irradiation. From scanning electron microscopy investigations in transmission modus (SEM$\mathrm{T}$ ) an average particle size of $12.3 \mathrm{~nm} \pm 1.4 \mathrm{~nm}$ (231 AuNP counted, Fig. 1) was deduced, confirming that the average particle size was maintained during ligand exchange and illumination.

With respect to further particle characterization, $\zeta$-potential measurements at different $\mathrm{pH}$ values were performed. 



4-Pentionic acid $\mathrm{Cu}(\mathrm{I}) \mathrm{Cl} /$ Ethylamine

1

2

3
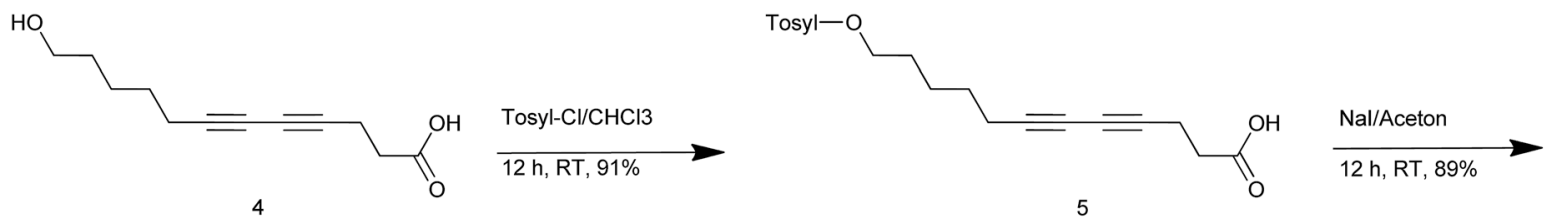

5

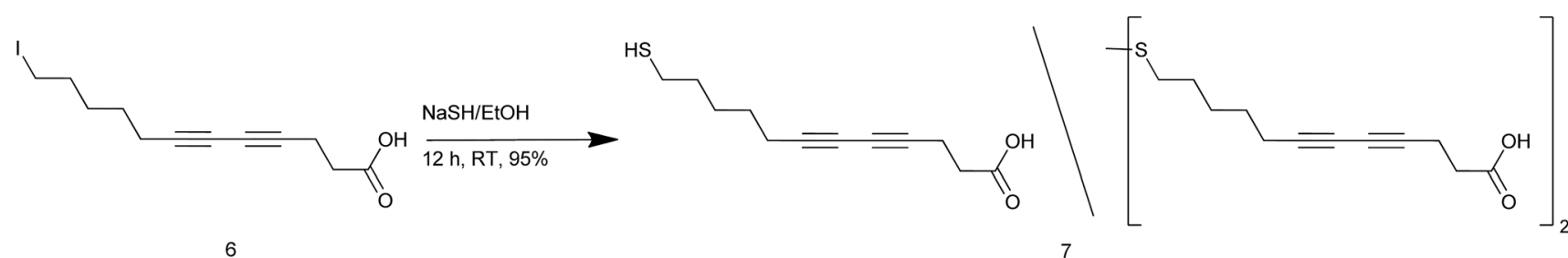

Scheme 2 Preparation of the ligand DA- $\mathrm{COOH}$.

At $\mathrm{pH} \geq 5$ the $c l \mathrm{DA}-\mathrm{COOH}-\mathrm{AuNP}$ exhibit a negative value for the $\zeta$-potential, reflecting the negative charge of the deprotonated carboxyl group. Whereas lowering the $\mathrm{pH}<5$ results in values for the $\zeta$-potential approaching zero, resembling protonation of the carboxylate group (see ESI $\dagger$ ).

For carboxyl-terminated AuNP a pH-dependent, reversible aggregation behavior upon hydrogen-bond-mediated aggregation processes are characteristic. ${ }^{14,35,36}$ These aggregation processes were monitored by UV-vis spectroscopy investigations with the $c l \mathrm{DA}-\mathrm{COOH}-\mathrm{AuNP}$ in order to prove the existence of terminal $\mathrm{COOH}$-groups after ligand polymerization (Fig. 2). We varied the $\mathrm{pH}$ value of the $c l \mathrm{DA}-\mathrm{COOH}-\mathrm{AuNP}$ aqueous dispersion between $\mathrm{pH} 9$ and $\mathrm{pH} 3$. At $\mathrm{pH} 9$ one sharp absorption band is observed, corresponding to the SPR of individual AuNP. Lowering the $\mathrm{pH}$ to 3 causes a red-shift and significant broadening of the SPR, reflecting the formation of



Fig. 1 Representative SEM-T image of CIDA-COOH-AuNP with histogram (inset). The particle size was determined to $12.3 \mathrm{~nm} \pm 1.4$ nm (based on 231 AuNP counted). aggregates. This aggregate formation is also observable by a color change of the dispersion from red to blue. Subsequent addition of $\mathrm{NaOH}$, thus raising the $\mathrm{pH}$ of the AuNP dispersion again to 9 , resulted in a color change back from blue to red and the UV-vis spectrum revealed again the significant absorption band for the SPR of individual AuNP, though with lower intensity. The slight decrease of absorption intensity arises from dilution effects upon adding $\mathrm{NaOH}$ or $\mathrm{HCl}$ solution, respectively (UV-vis spectra demonstrating the dilution effect on the UV-vis absorption intensity are included in the ESI $\dagger$ ). We repeated this process several times and observed always this characteristic switching between aggregated and individual particle state, thus proving the existence of free accessible terminal $\mathrm{COOH}$.



Fig. 2 UV-vis spectra of $\mathrm{pH}$ dependent agglomeration of irradiated clDa-COOH-AuNP, while alternately adding acids (blue) and bases (red) starting with $\mathrm{pH} 9$ (pink). 
In order to characterize the polymerization of the diacetylene moiety within the ligand shell upon UV irradiation, we performed surface enhanced Raman scattering (SERS) measurements. For this purpose samples of the dispersion containing DA-COOH-AuNP before and after irradiation, respectively, were drop-casted onto Au substrates.

The SERS spectrum of the particles before irradiation shows a signal at $2257 \mathrm{~cm}^{-1}$ (Fig. 3, red graph), which we assigned to the characteristic vibration of the diacetylene moiety. It should be noted that compared with the Raman spectrum of the unbound DA-COOH monomer in the solid state (see ESI $\dagger$ ) this signal is shifted by $194 \mathrm{~cm}^{-1}$. We ascribe this effect to the different measurement setups of Raman and SERS. This signal is no longer observed in the SERS spectrum of the irradiated sample (Fig. 3, blue graph). At the same time signals in the region between 1000 and $1600 \mathrm{~cm}^{-1}$ raise in intensity. Between $2800 \mathrm{~cm}^{-1}$ and $3000 \mathrm{~cm}^{-1} \mathrm{OH}$ stretching vibrations $(\nu(\mathrm{OH}))$ of the $\mathrm{COOH}$ group and of methylene groups $\left(\nu_{\mathrm{as}}\left(\mathrm{CH}_{2}\right)\right.$ and $\left.\nu_{\mathrm{s}}\left(\mathrm{CH}_{2}\right)\right)$ are located which remain unaffected by irradiation. Based on literature data ${ }^{34}$ these signals $\left(1000-1600 \mathrm{~cm}^{-1}\right)$ are attributed to carbon-carbon double bonds. The absence of the stretching vibrations of the carbon-carbon triple bond after irradiation, accompanied by the significant intensity increase of the vibrations of the carbon-carbon double bond, prove successful 1,4-polymerization. However, the signals assigned to the carbon-carbon double bond vibrations are very broad, which can be attributed to different polymer lengths. This is a consequence of the biradical homopolymerization mechanism. ${ }^{37,38}$ The fact that the non-irradiated sample (Fig. 3, red curve) showed low intensity signals in the region of the carboncarbon double bonds may result from measurement initiated polymerization (laser irradiation).

We have also performed TGA measurements in order to quantify the number of DA-COOH ligands on the AuNP surface.

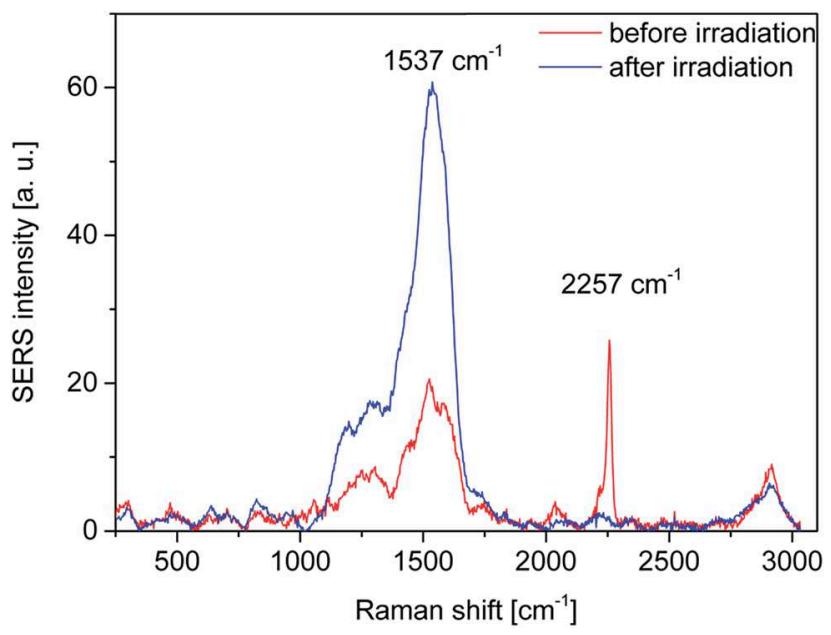

Fig. 3 SERS spectra of DA-COOH-AuNP before (red) and after (blue) irradiation with UV-light ( $254 \mathrm{~nm}$ ) for $15 \mathrm{~min}$. The signal at $2257 \mathrm{~cm}^{-1}$ is assigned to stretching vibrations of the carbon-carbon triple bond. The signals in the region of $1000-1600 \mathrm{~cm}^{-1}$ are attributed to the stretching vibrations of carbon-carbon double bonds. The signal broadening is attributed to different polymer lengths.
From these measurements an average of 2825 ligands per particle is deduced (3.6 ligands per $\mathrm{nm}^{2}$ ). This value is slightly higher than the coverage of diacetylene-PEG ligands on AuNP (2073/Au15; 3 ligands per $\left.\mathrm{nm}^{2}\right) .{ }^{21}$ With respect to the inaccuracy of the TGA method we conclude that the surface coverage is high enough to ensure a close packing density.

\section{Stability investigations}

The stability of the here prepared $c l \mathrm{DA}-\mathrm{COOH}-\mathrm{AuNP}$ refers to the concept of steric and electrostatic stabilization. First, due to the presence of terminal COOH-groups, the particles exhibit a pH-dependent surface charge in aqueous solution and are thus electrostatically stabilized, when the $\mathrm{COOH}$ group is deprotonated. This electrostatic stabilization is reflected in the previously described $\mathrm{pH}$-dependent agglomeration properties as well as in the $\zeta$-potential measurements. At pH 8 the particles exhibit a $\zeta$-potential of $-31 \mathrm{mV}$. Second, the polydentate nature of the $c l \mathrm{DA}-\mathrm{COOH}$ ligand guarantees steric stabilization due to geometric constraints formed by the polymeric ligand shell.

Electrostatically stabilized AuNP are strongly influenced by the ion density present in the solution. Upon addition of halide salts to the aqueous solutions of electrostatically stabilized AuNP, the electrical double layer surrounding the particles is reduced and the electrostatic repulsion is exceeded by van der Waals attraction, thus aggregation is induced.

Accordingly we investigated the influence of $\mathrm{NaCl}$ on $c l \mathrm{DA}-$ COOH-AuNP compared to non-irradiated DA-COOH-AuNP, in order to elucidate the benefit from the polymerization. Typically pure electrostatically stabilized AuNP tend to aggregate at $\mathrm{NaCl}$ concentrations of about $100 \mathrm{mM} .^{26}$

Moreover, recently published literature describes that the addition of a significant excess of halide salts could also lead to an exchange of the thiol ligand against the halide, due to halide anions diffusing through the ligand sphere and adsorbing on the Au-surface. As a consequence the particles are no longer stabilized by electrostatic or steric repulsive forces, finally leading to irreversible aggregation. This effect is also observable in the case of pure sterically stabilized particles, thus the stability towards $\mathrm{NaCl}$ also reflects the power of the steric stabilization. ${ }^{39,40}$

Additional information concerning the steric stabilization power can be gathered from DTT displacement reactions. On the one hand the small molecule DTT is known to have a high affinity to Au surfaces due to its two thiol groups and due to its size DTT should be able to penetrate the ligand shell more easily. On the other hand addition of excess DTT to ligand stabilized AuNP displaces thiol ligands from the particles surface nearly quantitatively, thereby forming aggregates resulting in insoluble precipitate formation. Thus we performed exchange experiments on non-irradiated DA-COOH-AuNP and on $c l \mathrm{DA}-\mathrm{COOH}-\mathrm{AuNP}$ with DTT in order to classify the effect of steric stabilization of monomeric and polymerized DA-COOH.

As a third parameter the prepared AuNP were investigated concerning heat stability. Integration of AuNP in a nanoelectronic setup is always accompanied with local heat evolution, thus heat stability is a further benefit with respect of building up nanoelectronic devices. 
Stability towards NaCl. The effect of $\mathrm{NaCl}$ addition on nonirradiated DA-COOH-AuNP and irradiated $c l \mathrm{DA}-\mathrm{COOH}-\mathrm{AuNP}$ was monitored by UV-vis spectroscopy. Therefore in each case the same volume of a solution of $\mathrm{NaCl}$ was added, so that an overall concentration of $0.15 \mathrm{M}$ or $0.3 \mathrm{M} \mathrm{NaCl}$ was obtained. UVvis spectra were recorded every $5 \mathrm{~min}$. after salt addition (after 20 minutes at intervals of $10 \mathrm{~min}$ ). Fig. 4 displays the sets of UVvis spectra obtained from the non-irradiated AuNP sample in $0.15 \mathrm{M}$ (Fig. 4a) and $0.3 \mathrm{M} \mathrm{NaCl}$ (Fig. 4c), as well as of the irradiated $c l$ DA-COOH-AuNP sample in $0.15 \mathrm{M}$ (Fig. $4 \mathrm{~b}$ ) and 0.3 $\mathrm{M} \mathrm{NaCl}$ (Fig. 4d).

In the case of the non-irradiated DA-COOH-AuNP in $0.15 \mathrm{M}$ $\mathrm{NaCl}$ a slight decrease of the SPR absorption intensity with at the same time slightly increasing absorption intensity in the longer wavelength regime is observed, indicating moderate stability of the particles in this medium. Moreover, in the higher ionic strength solution of $0.3 \mathrm{M} \mathrm{NaCl}$ the SPR is red-shifted and significantly broadened immediately after salt addition, reflecting the destabilization resulting in the formation of AuNP aggregates. This trend is consistent with electrostatically stabilized AuNP in a high ionic strength medium.

In contrast to that observation, in the case of $c l \mathrm{DA}-\mathrm{COOH}-$ AuNP, the SPR absorption of the particles in $0.15 \mathrm{M}$ is unaffected over $1 \mathrm{~h}$ and even at high ionic strength of $0.3 \mathrm{M} \mathrm{NaCl}$ only a low increase in absorption intensity in the longwavelength regime, pointing to aggregate formation, is observed. The maximum absorption retains at $523 \mathrm{~nm}$ in both cases and only a slow, continuous intensity decrease in the case of $0.3 \mathrm{M} \mathrm{NaCl}$ of the maximum absorption with time is observed.

This observation hints to additional steric stabilization of the particles which impedes aggregation, as observed in the non-irradiated samples. After $12 \mathrm{~h}$ incubation in $0.3 \mathrm{M} \mathrm{NaCl}$ the solution of irradiated $c l \mathrm{DA}-\mathrm{COOH}-\mathrm{AuNP}$ appeared colorless and the cuvette wall violet, obviously particles were attached to the cuvette surface. We were able to partially a)

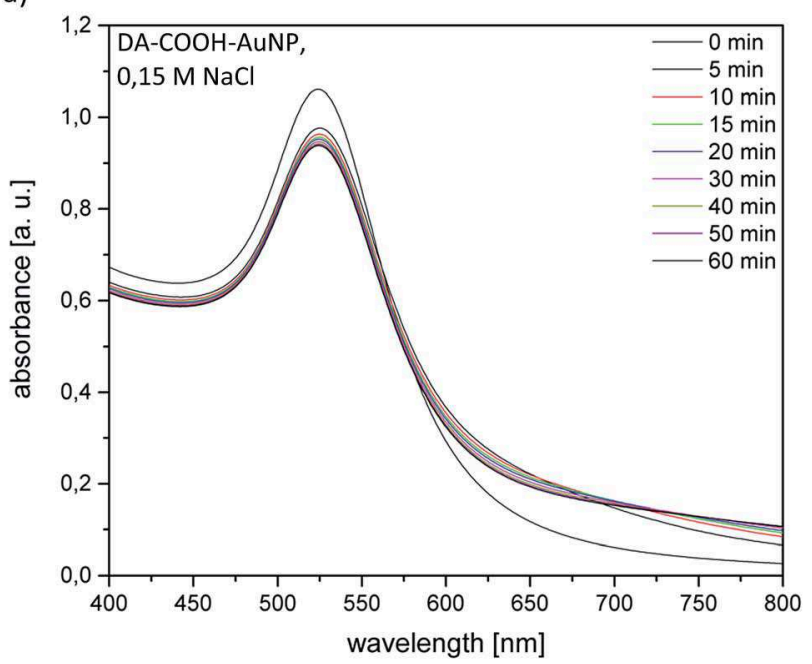

c)



b)

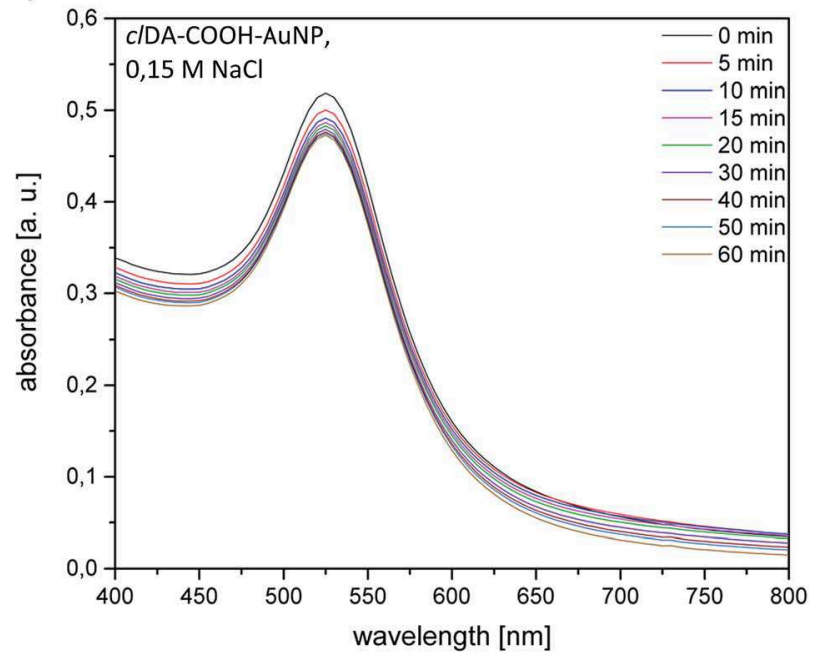

d)

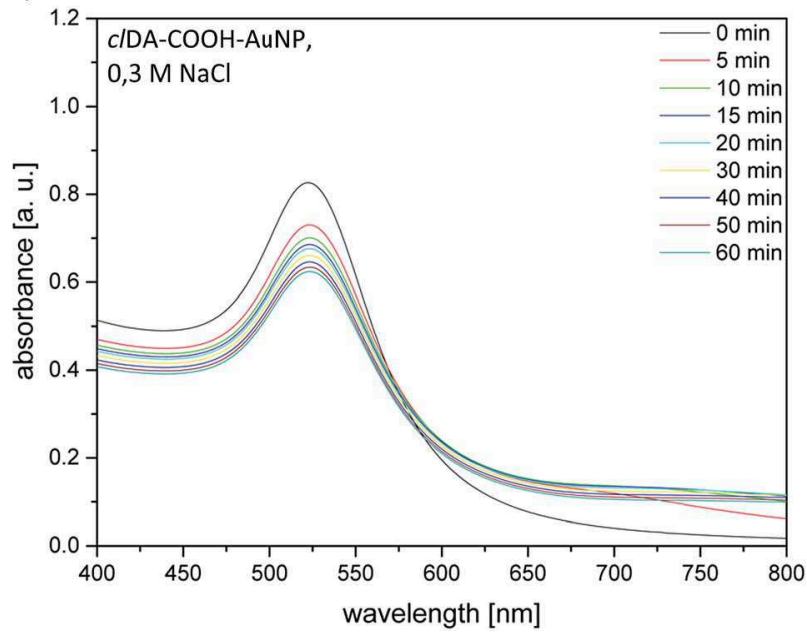

Fig. 4 UV-vis spectra of (a) non-irradiated DA-COOH-AuNP, $0.15 \mathrm{M} \mathrm{NaCl}$, (b) irradiated clDA-COOH-AuNP, $0.15 \mathrm{M}$, (c) non-irradiated DA$\mathrm{COOH}-\mathrm{AuNP}, 0.3 \mathrm{M} \mathrm{NaCl}$ and (d) irradiated ClDA-COOH-AuNP, $0.3 \mathrm{M} \mathrm{NaCl}$ before (black graph) and after addition of $\mathrm{NaCl}$ solution at different points in time after addition ( $5 \mathrm{~min}, 10 \mathrm{~min}, 15 \mathrm{~min} . .60 \mathrm{~min}$ ). 
detach the particles simply by adding phosphate buffer solution (0.1 M, pH 8) in combination with extensive ultrasonication (UV-vis spectrum of detached particles see ESI $\dagger$ ). Detachment of the particles was visible by reddening of the solution. We suppose that in contrast to the non-irradiated DA$\mathrm{COOH}-\mathrm{AuNP}$, addition of $\mathrm{NaCl}$ in this case mainly affects the electrical double layer. The steric stabilization is effective enough, to prevent aggregation, due to the geometric constraints of the nature of the polydentate ligand. As a consequence the particles' interactions of the terminal carboxylic group with the hydrophobic cuvette surface may increase, leading to an attachment of the particles to the cuvette wall. The fact that the particles could be detached in buffer solution additionally proofs high stability.

DTT competition. In order to elucidate the influence of the addition of DTT on non-irradiated DA-COOH-AuNP and on irradiated $c l \mathrm{DA}-\mathrm{COOH}-\mathrm{AuNP}$ we incubated samples of each particle type with excess DTT (1:50, see Experimental section) for $12 \mathrm{~h}$ at $60{ }^{\circ} \mathrm{C}$ and recorded an UV-vis spectrum in each case. The UV-vis spectra are depicted in Fig. 5a (DA-COOH-AuNP: blue solid line, $c l \mathrm{DA}-\mathrm{COOH}$-AuNP: red solid line). For reference purposes the UV-vis spectra of the respective particle types without DTT addition (Fig. 5a, DA-COOH-AuNP: blue dashed line, $c l \mathrm{DA}-\mathrm{COOH}-\mathrm{AuNP}$ : red dashed line) as well as the UV-vis spectrum of pure DTT after $12 \mathrm{~h}$ at $60{ }^{\circ} \mathrm{C}$ (Fig. 5a, black solid line) are plotted, too. After incubation of non-irradiated DACOOH-AuNP with excess DTT, particle aggregation was already observable by the naked eye. The initially red colored particle solution has turned colorless and a black precipitate is formed (Fig. 5a, inset, left sample). Corresponding to that observation the UV-vis spectrum (Fig. 5a, blue solid line) only shows the characteristic absorption signals for DTT itself and the characteristic SPR absorption band of the DA-COOH-AuNP at 522 $\mathrm{nm}$ (Fig. 5a, blue dashed line) has completely vanished. This result indicates significant ligand displacement of the DACOOH-ligand. Thus, steric constraints are obviously not sufficient to hinder the small DTT molecule to penetrate the ligand shell and reach the AuNP surface.

In contrast to this observation, the reddening of the solution in the case of $c l \mathrm{DA}-\mathrm{COOH}$-AuNP was maintained after DTT incubation (Fig. 5a, inset, right sample) and no precipitate was formed. In the UV-vis spectrum the SPR absorption band is only slightly reduced in intensity and shifted from $522 \mathrm{~nm}$ to $528 \mathrm{~nm}$ (Fig. 5a, red solid line). Furthermore beside the SPR absorption band the characteristic absorption signals for DTT were detected. This observation indicates that for clDA-COOH-AuNP ligand displacement reactions occurred only in a very small amount. The observed intensity loss and red-shift may be a result of marginal ligand displacement. Additional SEM-T investigations of these particles after DTT incubation revealed that the particles are still present as individual particles and the metal core size was unaffected (Fig. 5b).

These results affirm our above described results concerning the stability towards NaCl. Steric shielding of the AuNP metal core in the case of clDA-COOH-AuNP is effective, too. Even the small molecule DTT is significantly hindered to penetrate the ligand shell for ligand replacement.


Fig. 5 (a) UV-vis spectra of non-irradiated DA-COOH-AuNP (blue solid line) and irradiated clDA-COOH-AuNP (red solid line) after incubation with DTT at $60{ }^{\circ} \mathrm{C}$. For reference purposes the UV-vis spectrum of non-irradiated DA-COOH-AuNP (blue dashed line) and irradiated cIDA-COOH-AuNP (red dashed line) without DTT, respectively, as well as the UV-vis spectrum of DTT (black solid line) are also displayed. Inset: photography showing solutions of non-irradiated DA$\mathrm{COOH}-\mathrm{AuNP}$ (left) and irradiated ClDA-COOH-AuNP (right) after addition of DTT. (b) SEM-T image of irradiated CIDA-COOH-AuNP after incubation with DTT at $60^{\circ} \mathrm{C}$. Mean particle size $13.4 \mathrm{~nm} \pm 1.2 \mathrm{~nm}$ (156 particles counted).

\section{Thermal stability}

Potential effects of heating on irradiated clDA-COOH-AuNP were investigated by time dependent UV-vis spectroscopy of a particle dispersion in buffer solution $\left(\mathrm{pH}\right.$ 8) heated up to $50{ }^{\circ} \mathrm{C}$ (see $\operatorname{ESI} \dagger$ ) and up to $80{ }^{\circ} \mathrm{C}$ for $5 \mathrm{~h}$. Fig. 6a depicts the UV-vis spectra taken every hour at $80{ }^{\circ} \mathrm{C}$. Remarkably, during $5 \mathrm{~h}$, which represent harsh conditions for ligand stabilized AuNP, no significant change of the SPR absorption band is observed.

Additionally we performed heating cycles and monitored the hydrodynamic radii by DLS measurements during repeatedly warming and cooling between $20{ }^{\circ} \mathrm{C}$ and $70{ }^{\circ} \mathrm{C}$. The time dependent evolution of the hydrodynamic radii is displayed in Fig. $6 \mathrm{~b}$.

During the 3 times heating and cooling no obvious change of the hydrodynamic diameter is detected, thus aggregation upon 


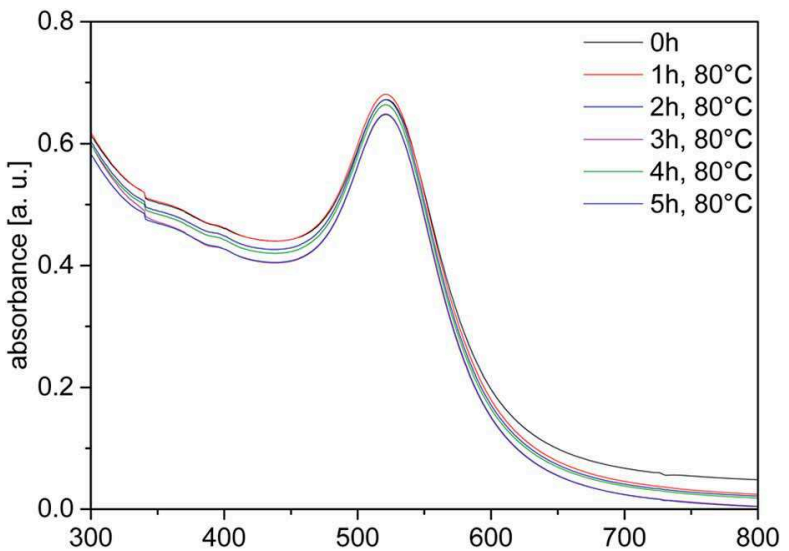

a)

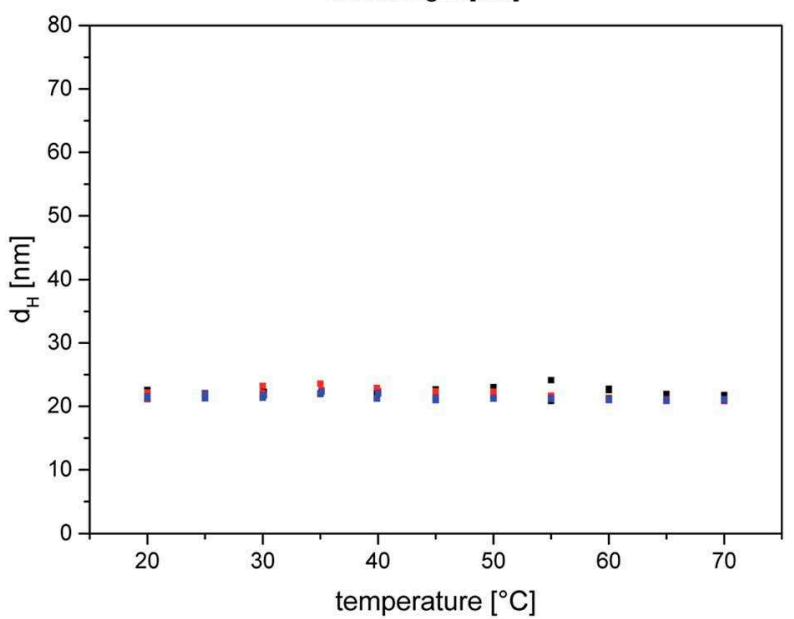

b)

Fig. 6 (a) UV-vis spectra recorded on a dispersion of cIDA-COOHAuNP in buffer solution $\left(\mathrm{pH} 8\right.$ ) heated at $80^{\circ} \mathrm{C}$ for $5 \mathrm{~h}$. (b) Evolution of the hydrodynamic radii $\left(d_{H}\right)$ of $c / D A-C O O H-A u N P$ during 3 heating and cooling cycles switching repeatedly between $20{ }^{\circ} \mathrm{C}$ and $70{ }^{\circ} \mathrm{C}$ forth and back.

temperature induced destabilization of the particles can be excluded. These observations confirm the extraordinary high stability of the prepared $c l \mathrm{DA}-\mathrm{COOH}-\mathrm{AuNP}$.

\section{Electrical characterization of individual $c$ DA-COOH-AuNP}

In order to investigate the electrical transport characteristics of the prepared $c l \mathrm{DA}-\mathrm{COOH}-\mathrm{AuNP}$ we applied the same setup as already described in our previous investigations on mercaptoundecanoic acid (MOA) stabilized AuNP. ${ }^{\mathbf{1 6}}$

Individual or at least a few $c l \mathrm{DA}-\mathrm{COOH}-\mathrm{AuNP}$ were immobilized by drop-casting a solution of $c l \mathrm{DA}-\mathrm{COOH}-\mathrm{AuNP}$ on the specially designed electrode structures (see Experimental section).

While drying capillary forces lead to immobilization of a single or at least a few clDA-COOH-AuNP in 10 cases. Fig. 7 depicts an exemplary SEM image of a resulting device used for the electrical characterization.

These functional $c l \mathrm{DA}-\mathrm{COOH}-\mathrm{AuNP}$ devices exhibited more than 10 reproducible cyclic $I / U$-measurements between $-1 \mathrm{~V}$ and $+1 \mathrm{~V}$. The obtained $I / U$-curves revealed a nonlinear current/

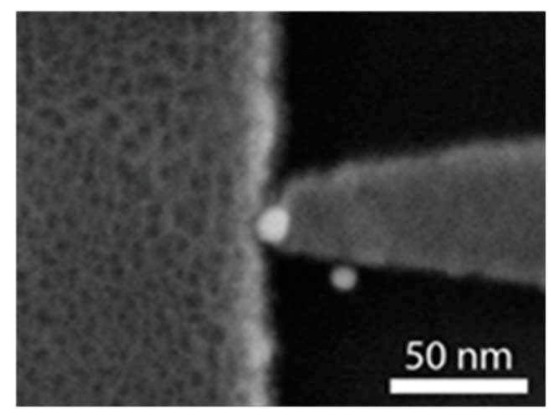

Fig. 7 Exemplarily SEM image of the setup used to electrically characterize an individual CIDA-COOH-AuNP immobilized in between a Pt- and a AuPd-electrode comprising a gap of about $13 \mathrm{~nm}$.

voltage dependence corresponding to an electron tunneling mechanism which can be described by the Simmons model as introduced previously. ${ }^{15,41,42}$

In Fig. 8a a characteristic tunneling curve and the corresponding Simmons fit are shown. The current signal gets remarkable noisy for voltages above $0.5 \mathrm{~V}$ and the noise rises with higher voltages. Moreover, for voltages above $1 \mathrm{~V}$ instabilities are observed pointing to a beginning destruction of the device. This unusual characteristic, compared with investigations performed previously on comparable AuNP-devices based on AuNP capped with several short organic molecules ${ }^{15,16,43}$ is found for all recorded data on $c l \mathrm{DA}-\mathrm{COOH}-\mathrm{AuNP}$ devices.

This finding indicates that the noise is correlated to the specific kind of $c l \mathrm{DA}-\mathrm{COOH}-\mathrm{AuNP}$ under investigation here. The experimental conductivity values for all clDA-COOH-AuNPdevices obtained were plotted in a histogram (Fig. 8b). Therefrom, a rather large variation of the conductance values of about 5 orders of magnitude, from $1 \mathrm{pS}$ to $70 \mathrm{nS}$ with a median of $55 \mathrm{pS}$, can be deduced.

In addition, most of the experimental conductivities are higher than the theoretical value of $11.8 \mathrm{pS}$ for electron tunneling through the $c l \mathrm{DA}-\mathrm{COOH}$ molecular shell that results from applying the single channel Landauer formula like a)

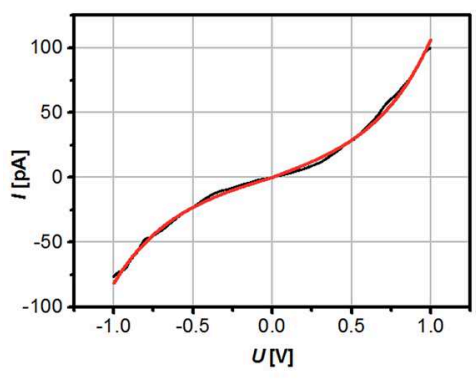

b)

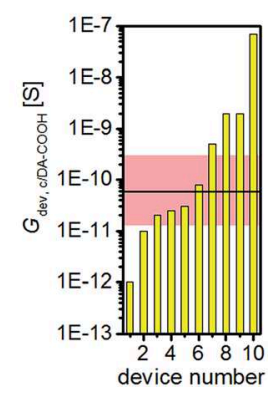

Fig. 8 (a) Current/voltage-characteristic: the black curve corresponds to the average of several measured cycles and the red curve to the Simmons fit. (b) Histogram of the conductance values of $10 \mathrm{clDA}$ $\mathrm{COOH}-$ AuNP devices at $1 \mathrm{~V}$. The horizontal black line shows the median and the light red bar marks values from $1 / 5$ times the median to 5 times the median. 
introduced in literature before. ${ }^{\mathbf{1 6 , 2 5 , 4 3 - 4 5}}$ These higher conductance values indicate a shorter electrical path through the molecular shell of $c l \mathrm{DA}-\mathrm{COOH}-\mathrm{AuNP}$ than expected based on the molecular length of DA-COOH.

Particularly, the higher experimental conductance can be interpreted as a mean reduction of the thickness of the molecular shell from $1.53 \mathrm{~nm}$ to $1.33 \mathrm{~nm}$ which corresponds to the length of 1 to 2 methylene groups.

These results together with the increasing noise of the $I / U$ curves for voltages above $0.5 \mathrm{~V}$ can be interpreted as variations in the cross-linkage within the ligand shell (polymers of different lengths, see Section 2) which leads to slightly different thicknesses of the DA-COOH-ligand shell around the AuNP. Due to the exponential dependence of the conductance through the DA-COOH-device from the tunnelling distance, i.e. the effective length of the clDA-COOH-molecule, an enhancement of the variations results. Here, further optimization is necessary to obtain more uniform polymerization products.

\section{Conclusions}

A specially designed ligand molecule consisting of a thiol group, a diacetylene unit and a terminal carboxylic group was prepared, suitable for applications in nanoelectronic devices based on AuNP. This ligand molecule, DA-COOH, was applied in a homogeneous ligand exchange reaction, starting from 11 $\mathrm{nm}$ citrate stabilized AuNP, in order to prepare respectively stabilized DA-COOH-AuNP. After ligand exchange the particles were exposed to UV light in order to induce polymerisation between neighbouring ligands containing diacetylene units assembled on the AuNP surface, thus forming a polymeric ligand shell (clDA-COOH-AuNP). Stability investigations towards $\mathrm{NaCl}$, DTT displacement reactions, and temperature were performed and reveal an extraordinary high stability. Additionally, individual particles could be successfully immobilized in between nanoelectrodes comprising gaps of 10 to 14 $\mathrm{nm}$. Electrical transport measurements revealed unexpected variations in conductance values. These could be attributed to small length differences of the tunnelling path through the polymerized ligand shell of $c l \mathrm{DA}-\mathrm{COOH}-\mathrm{AuNP}$.

Summarizing a novel extraordinary highly stable ligandAuNP composite was developed, exhibiting tailored functionalities, which reveal a high potential for nanoelectronic devices based on AuNP. Beyond this specific application scenario, we are sure that the extraordinary stable AuNP introduced here will be of interest for other fields of applications, which require high chemical and thermal particle stability in aqueous solvents.

\section{Acknowledgements}

This work was financially supported by the Excellence Initiative of the German federal and state government (Dean's Seed Fund Project "PolyTemp"), by the Jülich Aachen Research Alliance (JARA), and by the German Research Foundation (DFG; contracts Si 609/16-1 and Ka 1819/7-1). We further thank Svenja Bourone (M. Sc.) for performing IRRAS measurements, as well as Sophia Knecht (B. Sc.) and Christina Zitlau for their support in synthetic work as well as Dr Corinna Kaulen and Dr Michael Noyong for helpful discussions on the manuscript.

\section{Notes and references}

1 G. Schmid, Nanoparticles - From Theory to Application, WileyVCH, Weinheim, Germany, 2011.

2 X. Liu, M. Yu, H. Kim, M. Mameli and F. Stellacci, Nat. Commun., 2012, 3, 1182, DOI: 10.1038/ncomms2155.

3 B. Fresch and F. Remacle, J. Phys. Chem. C, 2014, 118(18), 9790-9800.

4 X. Gao, Y. Lu, M. Liu, S. He and W. Chen, J. Mater. Chem. C, 2015, 3, 4050-4056.

5 W. Wei, Y. Lu, W. Chen and S. Chen, J. Am. Chem. Soc., 2011, 133, 2060-2063.

6 J. Broda, G. Schmid and U. Simon, Struct. Bonding, 2014, 161, 189-241.

7 M. Homberger and U. Simon, Philos. Trans. R. Soc., A, 2010, 368, 1405-1453.

8 M.-C. Daniel and D. Astruc, Chem. Rev., 2004, 104(1), 293-346. 9 P. M. Tiwari, K. Vig, V. A. Dennis and S. R. Singh, Nanomaterials, 2011, 1, 31-63.

10 K. Saha, S. S. Agasti, C. Kim, X. Li and V. M. Rotello, Chem. Rev., 2012, 112(5), 2739-2779.

11 E. C. Dreaden, M. A. Mackey, X. Huang, B. Kang and M. A. ElSayed, Chem. Soc. Rev., 2011, 40, 3391-3404.

12 E. C. Dreaden, A. M. Alkilany, X. Huang, C. J. Murphy and M. A. El-Sayed, Chem. Soc. Rev., 2012, 41, 2740-2779.

13 A. Buchkremer, M. F. Beckmann, M. Linn, J. Ruff, R. R. Rosencrantz, G. von Plessen, G. Schmitz and U. Simon, Mater. Res. Express, 2014, 1(4), 045015, DOI: 10.1088/2053-1591/1/4/045015.

14 C. Kaulen, M. Homberger, S. Bourone, N. Babajani, S. Karthäuser, A. Besmehn and U. Simon, Langmuir, 2014, 30(2), 574-583.

15 N. Babajani, P. Kowalzik, R. Waser, M. Homberger, C. Kaulen, U. Simon and S. Karthäuser, J. Phys. Chem. C, 2013, 117(42), 22002-22009.

16 N. Babajani, C. Kaulen, M. Homberger, M. Mennicken, R. Waser, U. Simon and S. Karthäuser, J. Phys. Chem. C, 2014, 118(46), 27142-27149.

17 M. Brust, D. Bethell, D. J. Schiffrin and C. J. Kiely, Adv. Mater., 1995, 7(9), 795-797.

18 C. Guarise, L. Pasquato and P. Scrimin, Langmuir, 2005, 21(12), 5537-5561.

19 T. Peterle, A. Leifert, J. Timper, A. Sologubenko, U. Simon and M. Mayor, Chem. Commun., 2008, 3438-3440.

20 L. Srisombat, A. C. Jamison and T. R. Lee, Colloids Surf., A, 2011, 390, 1-19.

21 D. Bartczak and A. G. Kanaras, Langmuir, 2010, 26(10), 70727077.

22 Y. Song, L. M. Klivansky, Y. Liu and S. Chen, Langmuir, 2011, 27, 14581-14588.

23 H. Menzel, M. D. Mowery, M. Cai and C. E. Evans, Macromol. Symp., 1999, 142, 23-31.

24 J. C. Love, L. A. Estroff, J. K. Kriebel, R. G. Nuzzo and G. M. Whitesides, Chem. Rev., 2005, 105(4), 1103-1169. 
25 S. Karthäuser, J. Phys.: Condens. Matter, 2011, 23, 013001, DOI: 10.1088/0953-8984/23/1/013001.

26 S. K. Ghosh and T. Pal, Chem. Rev., 2007, 107(11), 4797-4862. 27 J. Turkevich, P. C. Stevenson and J. Hillier, Discuss. Faraday Soc., 1951, 11, 55-75.

28 M. Manheller, S. Trellenkamp, R. Waser and S. Karthäuser, Nanotechnology, 2012, 23, 125302-125308.

29 Y. Cui, M. T. Björk, A. Liddle, C. Sönnichsen, B. Boussert and A. P. Alivisatos, Nano Lett., 2004, 4(6), 1093-1098.

30 Y. Xing and G. A. O'Doherty, Org. Lett., 2009, 11(5), 11071110.

31 A. Sevin, W. Chodkiewicz and P. Cadiot, Bull. Soc. Chim. Fr., 1974, 913-917.

32 P. C. B. Page, R. D. Wilkes and D. Reynolds in Comprehensive Organic Functional Group Transformations: Synthesis: carbon with one heteroatom attached by a single bond, ed. A. R. Katritzky, O. Meth-Cohn and C. W. Rees, Elsevier, 1995, pp. 213-214.

33 C. D. Bain, H. A. Biebuyck and G. M. Whitesides, Langmuir, 1989, 5, 723-727.

34 G. Sokrates, Infrared and Raman Characterisitc Group Frequencies, John Wiley \& Sons Ltd., New York, 2001.
35 G. Li, T. Wang, S. Bhosale, Y. Zhang and J.-H. Fuhrhop, Colloid Polym. Sci., 2003, 281, 1009-1103.

36 J.-Y. Shim and V. K. Gupta, J. Colloid Interface Sci., 2007, 316(2), 977-983.

37 A. Prock, M. L. Shand and R. R. Chance, Macromolecules, 1982, 15, 238-241.

38 G. N. Patel, R. R. Chance, E. A. Turi and Y. P. Khanna, J. Am. Chem. Soc., 1978, 100(21), 6644-6649.

39 D. Zopes, B. Stein, S. Mathur and C. Graf, Langmuir, 2013, 29, 11217-11226.

40 B. Stein, D. Zopes, M. Schmudde, R. Schneider, A. Mohsen, C. Goroncy, S. Mathur and C. Graf, Faraday Discuss., 2015, 181, 85-102.

41 J. G. Simmons, J. Appl. Phys., 1963, 34(6), 1793-1803.

42 J. G. Simmons, J. Appl. Phys., 1963, 34(9), 2581-2590.

43 M. Manheller, S. Karthäuser, R. Waser, K. Blech and U. Simon, J. Phys. Chem. C, 2012, 116, 20657-20665.

44 Y. Imry and R. Landauer, Rev. Mod. Phys., 1999, 71, 306-312. 45 A. Salomon, D. Cahen, S. Lindsay, J. Tomfohr, V. B. Engelkes and C. D. Frisbie, Adv. Mater., 2003, 15, 1881-1890. 